\title{
PKM Sosialasi Aplikasi Pengelolaan Laboratorium Pertanian Fakultas Pertanian Universitas Lancang Kuning
}

\author{
Nurliana Nasution ${ }^{1}$, David Setiawan ${ }^{2}$, Mhd Arief Hasan ${ }^{3}$ \\ ${ }^{1,3}$ Program Studi Teknik Informatika Universitas Lancang Kuning, Pekanbaru, Indonesia \\ 2 Program Studi Teknik Elektro Universitas Lancang Kuning, Pekanbaru, Indonesia \\ (nurliananst@unilak.ac.id, dsetia@unilak.ac.id, m.arif@unilak.ac.id)
}

\begin{abstract}
Abstrak: Laboratorium Fakultas Pertanian merupakan unit pelaksanana manajemen yang memfasilitasi dan mendukung pelaksanaan kegiatan riset dan pengabdian civitas akademika Universitas Lancang Kuning. Selama ini laboratorium Fakultas Pertannian Universitas Lancang Kuning, mencatat dan mendata seluruh data laboratorium masih secara manual dengan menggunakan berkas Microsoft Excel. Beranjak dari permasalahan ini sepenuhnya sudah dilakukan penelitian di Laboratorium Fakultas Pertanian. Dari penelitian tersebut sudah lahir sebuah aplikasi manajemen laboratorium di Fakultas Pertanian Universitas Lancang Kuning. Namun aplikasi tersebut belum tersosialisasikan dengan baik, setelah diadakan diskusi dengan pihak Fakultas Pertanian Universitas Lancang Kuning (FAPERTA-UNILAK), diambil kesimpulan diperlukan pelatihan agar manfaat dari aplikasi yang sudah dibuat bisa dirasakan oleh civitas akademika Fakultas Pertanian Universitas Lancang Kuning. Pelatihan ini dibuat dalam format program Pengabdian Kepada Masyarakat(PKM).Metode pelaksanaan kegiatan IBM ini dilakukan di Fakultas Pertanian Universitas Lancang Kuning dengan metode ceramah, ujicoba sistem, Tanya jawab dan evaluasi. Metode ceramah diberikan saat pemberian materi dengan menggunakan power point, handout materi, poster, dan alat peraga berupa simulasi penggunaan sistem secara online. Pelaksanaan kegiatan Pengabdian kepada Masyarakat "Sosialisasi Aplikasi Manajemen Laboratorium Studi Kasus Laboratorium Pertanian" dilaksanakan di Ruang Laboratorium Fakultas Pertanian Universitas Lancang Kuning pada tanggal 16 Mei 2016 telah dilaksanakan 100\% program yaitu: Simulasi Manajemen Aplikasi Laboratorium Fakultas Pertanian di Universitas Lancang Kuning. Evaluasi kegiatan diberikan melalui angket kuisioner terhadap seluruh peserta pelatihan.
\end{abstract}

Kata Kunci: Aplikasi, Laboratorium, Pelatihan, Pertanian,PKM,

Abstract: The Faculty of Agriculture Laboratory is a management implementation unit that facilitates and supports the implementation of research activities and service of the academic community of Lancang Kuning University. During this time, the laboratory of the Faculty of Agriculture, University of Lancang Kuning, recorded and recorded all the laboratory data still manually using Microsoft Excel files. Departing from this problem has been completely researched in the Laboratory of the Faculty of Agriculture. From this research, a laboratory management application was born in the Faculty of Agriculture, University of Lancang Kuning. However, the application has not been well socialized, after a discussion with the Faculty of Agriculture, University of Lancang Kuning (FAPERTA-UNILAK), concluded that training is needed to benefit made can be felt by the academic community of the Faculty of Agriculture, University of Lancang Kuning. This training is made in the format of the Community Service (PKM) program. The method of implementation of IBM activities is done at the Faculty of Agriculture, University of Lancang Kuning with lecture methods, system testing, question and answer and evaluation. Lecture methods are given when giving material using power point, handout material, posters, and props in the form of simulation of online system use. Implementation of Community Service "Socialization Application Management Case Studies Laboratory Laboratory of Agriculture" held in the Laboratory of the Faculty of Agriculture, University of Yellow on May 16, 2016 was 100\% implemented programs: Application Management Simulation Laboratory of the Faculty of Agriculture at the University of Lancang Kuning Evaluation of activities is provided through a questionnaire questionnaire to all training participants.

Keywords: Agriculture, Applications, Community Service, Laboratories, Training, 


\section{Pendahuluan}

\subsection{Latar Belakang Masalah}

Laboratorium Fakultas Pertanian merupakan unit pelaksanana manajemen yang memfasilitasi dan mendukung pelaksanaan kegiatan riset dan pengabdian civitas akademika Universitas Lancang Kuning. Sesuai dengan visi dan misi dari Universitas Lancang Kuning menjadi Universitas Unggul pada tahun 2030 bertaraf nasional. Maka unit laboratoriumm membutuhkan aplikasi yang dapat memberikan efektifiats dan efisiensi, yang dapat menampung seluruh data laboratorium yang terdapat di lingkungan Fakultas Pertanian Universitas Lancang Kuning.

Selama ini laboratorium Fakultas Pertannian Universitas Lancang Kuning, mencatat dan mendata seluruh data laboratorium masih secara manual dengan menggunakan berkas Microsoft Excel. Hal tersebut dianggap kurang efisien dan efektif, karena data laboratorium itu tidak disimpan secara terpusat dan terstruktur, yang menyebabkan data tersebut mudah hilang dan tidak bisa diakses secara umum oleh warga luar yang ingin melihat informasi mengenai laboratorium-laboratorium yang terdapat di lingkungan Fakultas Pertanian Universitas Lancang Kuning.

Beranjak dari permasalahan ini sepenuhnya sudah dilakukan penelitian di Laboratorium Fakultas Pertanian. Dari penelitian tersebut sudah lahir sebuah aplikasi manajemen laboratorium di Fakultas Pertanian Universitas Lancang Kuning. Aplikasi merupakan perangkat lunak komputer dengan tujuan tertentu(Hasan \& Zamzami, 2017). Pemanfaatan aplikasi ini akan memberikan nilai tambah bagi Laboratorium Fakultas Pertanian Universitas Lancang Kuning (Nasutio \& Hasan, 2017). Aplikasi ini nantinya pasti memberikan informasi. Informasi yang dihasilkan bermanfaat dalam pengambilan keputusan yang tepat(Moh, 2012).

Namun aplikasi tersebut belum tersosialisasikan dengan baik, setelah diadakan diskusi dengan pihak Fakultas Pertanian Universitas Lancang Kuning (FAPERTA-UNILAK), diambil kesimpulan diperlukan pelatihan agar manfaat dari aplikasi yang sudah dibuat bisa dirasakan oleh civitas akademika Fakultas Pertanian Universitas Lancang Kuning. Pelatihan ini dibuat dalam format program Pengabdian Kepada Masyarakat(PKM). Penulis memikirkan perlu pentingnya dilakukan PKM ini dengan tujuan aplikasi ini bisa memberikan manfaat kepada mitra yakni FAPERTA-UNILAK (Nasution et al., 2020; Nasution \& Hasan, 2019).

Dalam pelatihan ini juga diikutsertakan Fakultas Kehutanan sebagai mitra. Karena Fakultas Kehutanan juga mempunyai masalah sama akan sebuah sistem yang dapat mengakomodir kebutuhan laboratorium mereka.

\subsection{Permasalahan Mitra}

Secara umum permasalahan yang terjadi di mitra ada dua : Pertama, Mitra disini yakni pihak Fakultas Pertanian Universitas Lancang Kuning yang menginginkan agar terciptanya mutu laboratorium terlihat dari penggunaan teknologi informasi yang digunakan. Mulai dari pendataan invetarisasi laboratorium hingga prosedur pemakaian atau peminjaman inventaris yang ada (Afuan \& Permadi, 2013; Afyenni, 2014; Garside \& Utama, 2016; Luthfi \& Riasti, 2013; Ricky, 2010). Dengan adanya aplikasi yang sudah diciptakan nantinya bisa membantu pihak Fakultas Pertanian Universitas Lancang Kuning dalam membantu permasalahan yang terjadi. Kedua, Aplikasi Manajemen Laboratorium Fakultas Pertanian Universitas Lancang Kuning yang telah dibuat sebelumnya. Belum semuanya memahami prosedur penggunaannya. 
Disamping itu aplikasi ini masih butuh masukan agar bisa dikembangkan lebih baik dan optimal

\section{Metode}

Metode pelaksanaan kegiatan IBM ini dilakukan di Fakultas Pertanian Universitas Lancang Kuning dengan metode ceramah, ujicoba sistem, Tanya jawab dan evaluasi. Metode ceramah diberikan saat pemberian materi dengan menggunakan power point, handout materi, poster, dan alat peraga berupa simulasi penggunaan sistem secara online. Metode ujicoba sistem diberikan kepada operator Laboratorium Faperta Unilak yang nantinya terlibat dalam penggunaan sistem yakni berupa pengelolaan web laboratorium, input data inventarisasi, registrasi user, peminjaman alat, pemakaian habis pakai. cetak faktur, dan backup program. Metode evaluasi dilakukan pada awal dan akhir pelatihan. Hal ini untuk mengetahui tingkat pengetahuan peserta dan menerima masukan untuk perbaikan sistem selanjutnya. Pendampingan dilaksanakan setelah semua rangkaian ceramah materi dan pelatihan selesai.

2.1 Kegiatan Penyuluhan (Ceramah) meliputi materi :

a. Pengenalan Aplikasi Manajemen Laboratorium

b. Prosedur Penggunaan Aplikasi Manajemen Laboratorium Secara Online Adapun prosedur tersebut meliputi

- Fitur yang tersedia dari Aplikasi

- Metode Penerapan Aplikasi

- Operator yang terlibat dalam penggunaan aplikasi

- Evaluasi Sistem

2.2 Kegiatan Pelatihan (praktek) meliputi

a. Pelatihan Pendaftaran User

b. Pelatihan Pendataan Interasi

c. Pelatihan Peminjaman Alat

d. Pelatihan Penggunaan Habis Pakai

e. Pelatihan Cetak Hasil

f. Pelatihan Backup Sistem

\section{Hasil dan Pembahasan}

Pelaksanaan kegiatan Pengabdian kepada Masyarakat "Sosialisasi Aplikasi Manajemen Laboratorium Studi Kasus Laboratorium Pertanian" dilaksanakan di Ruang Laboratorium Fakultas Pertanian Universitas Lancang Kuning pada tanggal 16 Mei 2016 telah dilaksanakan 100\% program yaitu: Simulasi Manajemen Aplikasi Laboratorium Fakultas Pertanian di Universitas Lancang Kuning. Kegiatan yang dilaksanakan berupa uji coba aplikasi kepada Orang Peserta yang terdiri atas :

1. Perwakilan dari Laboran Pertanian

2. Perwakilan dari Laboran Biologi

3. Perwakilan dari Laboran Kehutanan 


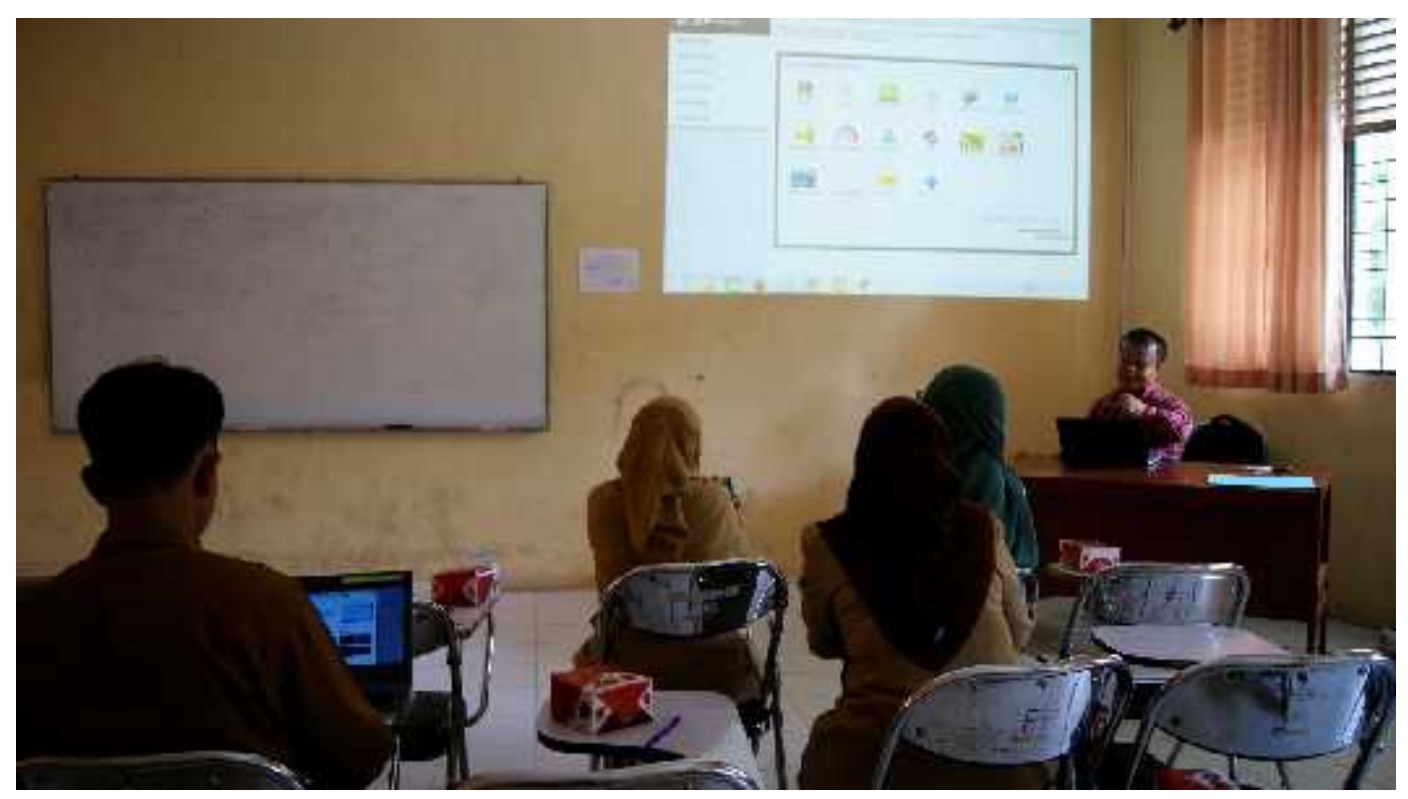

Gambar 1. Susasana Pelatihan

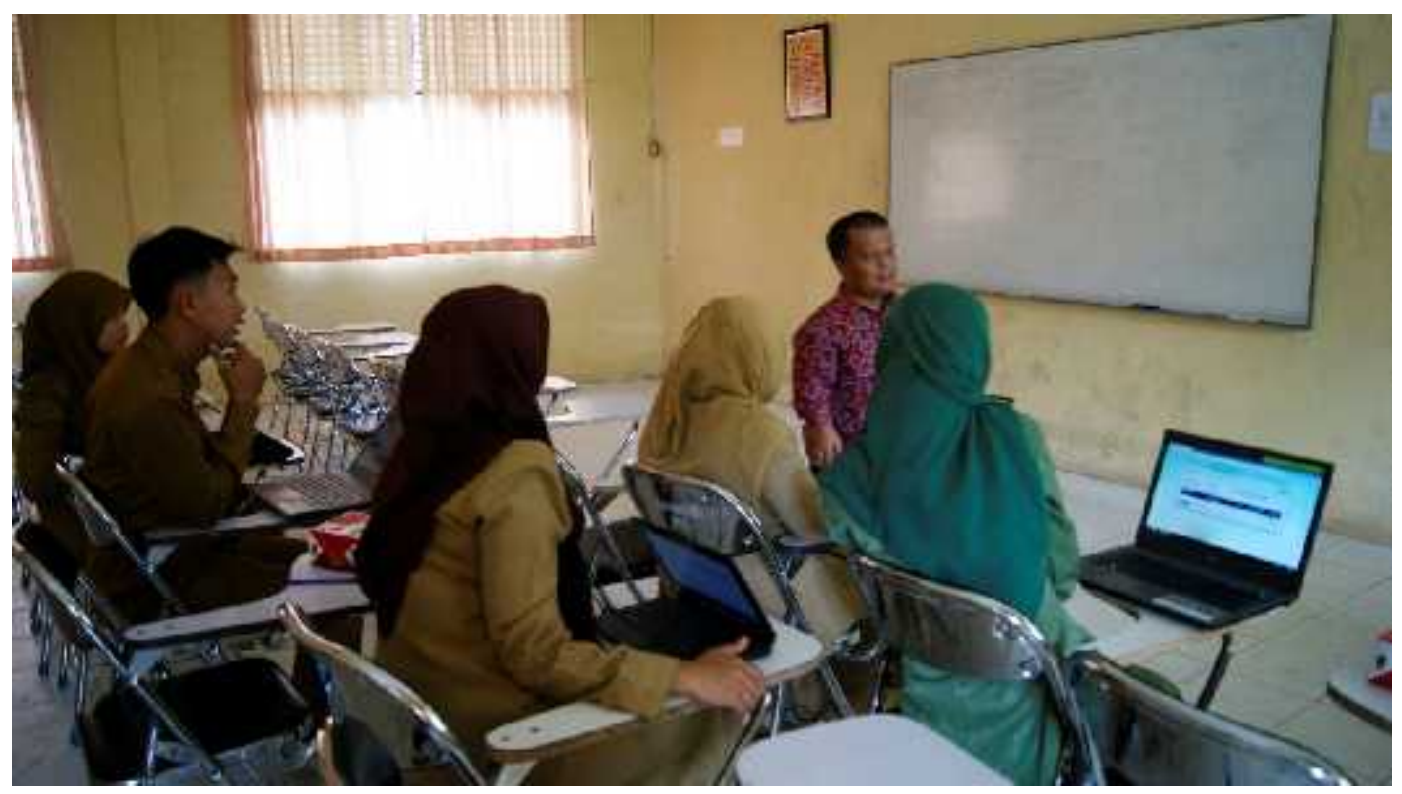

Gambar 2. Suasana Diskusi Peserta dengan Pemateri

\subsection{Persiapan Kegiatan}

Pada tahap awal pelaksanaan program dilaksanakan kegiatan berupa perancangan desain dan kegiatan pelatihan, persiapan peralatan, sosialisasi dan simulasi dengan peserta. Perancangan desain dan kegiatan pelatihan dilaksanakan bersama tim pengusul didasari oleh analisis situasi yang dibuat berdasarkan permasalahan yang dihadapi oleh Universitas Lancang Kuning. Perancangan ini dilaksanakan pada Bulan Januari 2016 yang juga melibatkan peran serta aktif peserta program pengabdian kepada masyarakat untuk membuat skala prioritas program yang dilaksanakan. Perencanaan ini berjalan dengan sangat baik berkat peranan aktif tim pelaksana dan peserta yang menjadi mitra program. 
Persiapan yang dilaksanakan berikutnya berupa persiapan peralatan dan bahan yang dilaksanakan dengan menyiapkan perangkat laptop/komputer sebagai media pendukung realisasi kegiatan, bahan pelatihan manajemen produksi (soal ujian online), Undangan Pelatihan kepada peserta,Kuisoner, wireless untuk mengakses internet dalam simulasi penggunaan website. Semua data sudah diinputkan kedalam website sebelum pelaksanaan kegiatan.

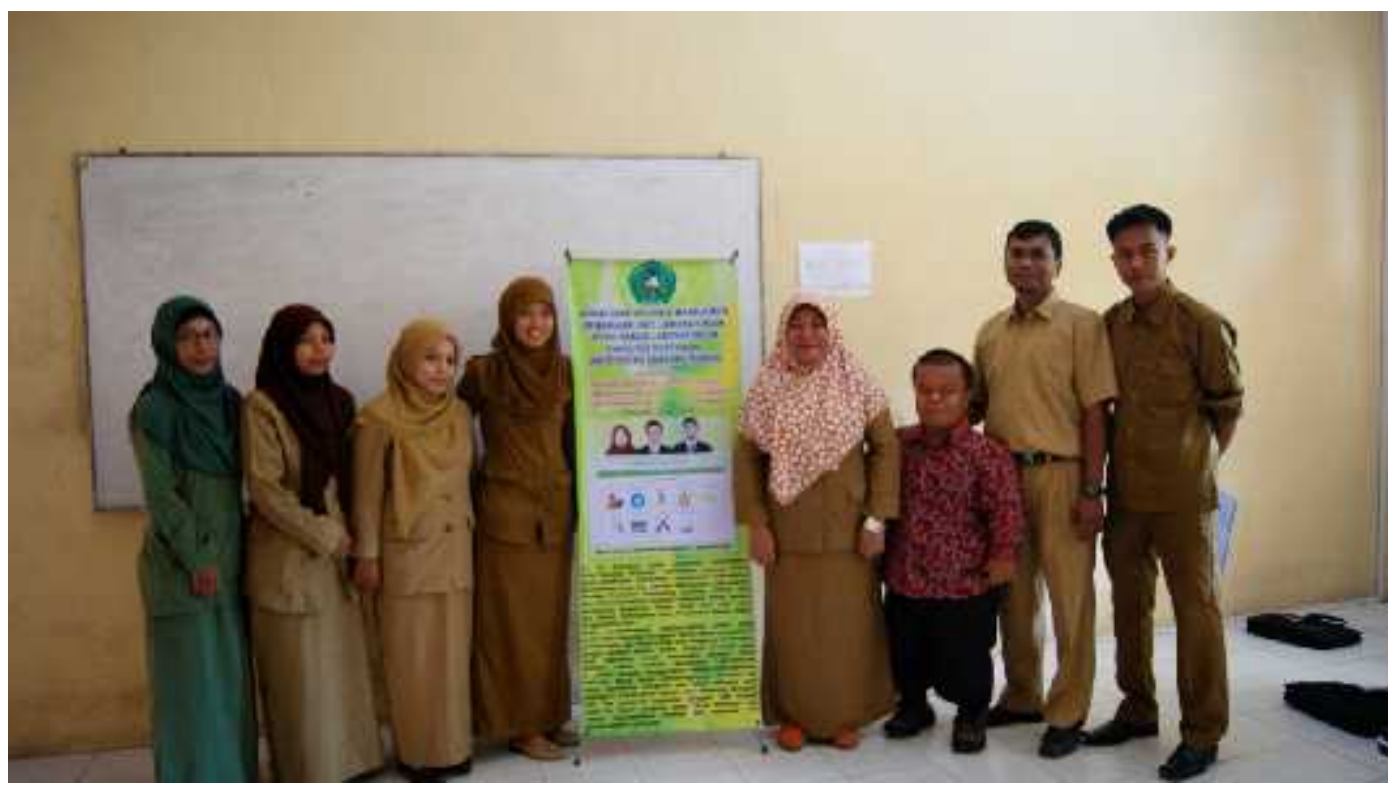

Gambar 3. Foto Pemateri Bersama Peserta

\subsection{Pelaksanaan Kegiatan}

Setelah semua peralatan dan bahan dilakukan. Maka tahapan selanjutnya pelaksanaan kegiatan. Kegiatan dilaksanakan kedalam 2 tahap :

a. Pendaftaran User dan Sosialsiasi Penggunaan Aplikasi Manajemen Laboratoriun

Sebelum peserta melaksanakan simulasi peserta dipandu cara mengintegrasikan database mahasiswa, alat, bahan habis pakai, yang ada di Laboratorium dengan aplikasi.Uraian kegiatan berupa pemahaman pentingnya penggunaan aplikasi Manajemen Laboratorium, fitur - fitur yang tersedia, mekanisme ujian.

Setelah peserta memahami mengenai penggunaan aplikasi tersebut kemudian Peserta mulai mengumpulkan data alat dan bahan habis pakai yang ada di Laboratorium Universitas Lancang Kuning

b. Pelaksanaan simulasi Aplikasi

Peserta diajarkan mengenai teknik penggunaan aplikasi, Mulai dari cara mahasiswa mendaftarkan alat, mendaftarkan user, proses peminjaman, proses pengembalian dan lain sebagainya. 


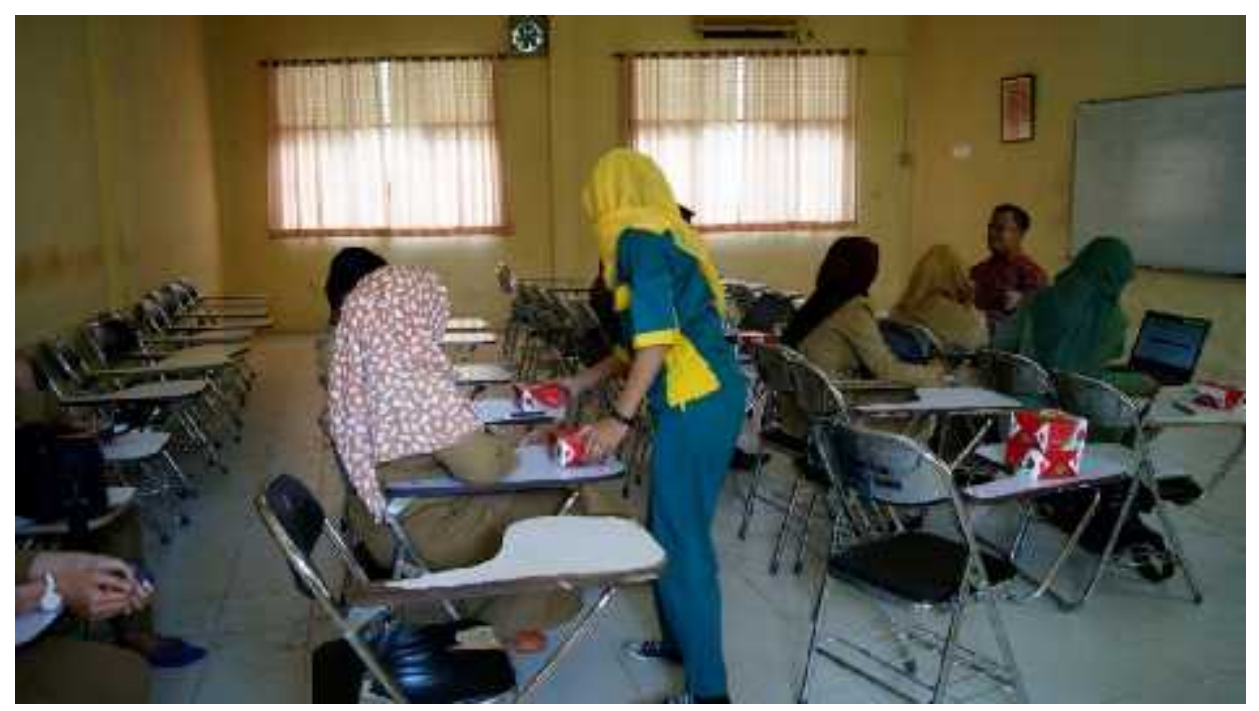

Gambar 4. Suasana Simulasi Aplikasi

Peserta didampingi langsung dalam pelaksanaan ujian oleh tim peneliti. Peneliti mengamati langsung mengenai kendala yang dihadapi langsung oleh peserta selama simulasi . Kendala tersebut direkam dan dicatat guna perbaikan sistem ke depan.

Seluruh peserta dapat melaksanakan ujian ini dengan baik. Hasil akhir yang diberikan dari simulasi ini berupa:

a. Peserta di haruskan mengisi kuisioner mengenai layanan sistem yang diberikan

b. Hasil akhir nilai dari peserta menjadi evaluasi bagi tim peneliti akan kemudahan dari penggunaan sistem.

c. Peserta diberikan sertifikat diberikan sertifikat atas partisipasi yang sudah diberikan.

\subsection{Evaluasi Kegiatan}

Evaluasi kegiatan diberikan melalui angket kuisioner terhadap seluruh peserta pelatihan. Berikut kesimpulan yang didapat dari hasil evaluasi peserta :

a. Setelah diadakan pelatihan pemahaman peserta semakin meningkat akan pentingnya penggunaan aplikasi manajemen Laboratorium.

b. Peserta memahami dengan baik bagaimana cara penggunaan Aplikasi Manajemen Laboratorium.

c. Peserta juga sudah bisa menginputkan beberapa variabel dalam aplikasi seperti (Input data alat, bahan habis pakai, peminjaman alat, pemakaian habis pakai, dan penulisan artikel website)

d. Peserta sangat antusias untuk menerapkannya di Laboratorium masing-masing.

e. Laboran yang tidak mengikuti pelatihan ini setelah acara juga ingin memasang aplikasi ini laboratorium mereka.

\section{Kesimpulan}

Adanya kegiatan pengabdian kepada masyarakat program IbM Tahun Anggaran 2016 untuk Laboran di Universitas Lancang Kuning Pekanbaru ini, permasalahan yang dihadapi mitra dapat segera teratasi dalam rangka meningkatkan pendapatan dan pengetahuan mitra. Dari kegiatan IbM ini diperoleh hasil yang cukup baik yaitu sebagai berikut 
a. Aplikasi Manajemen Laboratorium Berbasis Online untuk masing masing laboratorium di Universitas Lancang Kuning

b. pelatihan pemahaman peserta semakin meningkat akan pentingnya penggunaan aplikasi manajemen Laboratorium

c. Peserta juga sudah bisa menginputkan beberapa variabel dalam aplikasi seperti (Input data alat, bahan habis pakai, peminjaman alat, pemakaian habis pakai, dan penulisan artikel website)

d. Peserta sangat antusias untuk menerapkannya di Laboratorium masing-masing.

Dalam rangka meningkatkan transfer teknologi kepada Laboran di Fakultas Pertanian hendaknya kegiatan-kegiatan seperti terus rutin dilaksanakan dikarenakan labor merupakan unit terpenting dalam pelaksanaan tridarma pendidikan sehingga kemampuan skil laboran semakin meningkat sekaligus juga bagian dari percepatan untuk UNILAK unggul 2030.

\section{Ucapan Terima Kasih}

Terima kasih kami ucapkan kepada Fakultas IImu Komputer Universitas Lancang Kuning melalui UP2M telah memfasilitasi pelaksanaan kegiatan Pengabdian Kepada Masyarakat sebagai wujud pelaksanaan tridarma perguruan tinggi bagi pendidik. Terimakasih juga di ucapkan kepada tim solid pelaksana Pengabdian Kepada Masyarakat

\section{Daftar Pustaka}

Afuan, L., \& Permadi, I. (2013). Rancang Bangun Sistem Infomasi Laboratorium (SI LAB) Berbasis WEB Di Teknik Informatika UNSOED. Prosiding SNST Fakultas Teknik, 1(1), 2632.

Afyenni, R. 2014. (2014). Perancangan Data Flow Diagram untuk Sistem Informasi Sekolah (Studi Kasus Pada SMA Pembangunan Laboratorium UNP). Teknoif, 2(1), 35-39.

Garside, A. K., \& Utama, D. M. (2016). Perancangan Sistem Informasi Laboratorium Teknik Industri Universitas Muhammadiyah Malang. Sentra, 6-11.

Hasan, M. A., \& Zamzami, Z. (2017). Rancang Bangun Sistem Informasi Pelayanan Angkutan Terminal Kota Pekanbaru Berbasis Online. Jurnal I Imu Komputer, 6(1), 8- 14. https://doi.org/10.33060/jik/2017/vol6.iss1.40

Luthfi, H. W., \& Riasti, B. K. (2013). Sistem Informasi Perawatan Dan Inventaris Laboratorium Pada Smk Negeri 1 Rembang Berbasis Web. Indonesian J urnal on Computer Science - Speed (IJCSS), 10(1), 83-91. https://doi.org/10.3112/SPEED.V3I3.1219

Moh, A. S. N. (2012). Sistem Informasi Manajemen Laboratorium ( SI MLAB ) ( Studi Kasus Laboratorium Progdi Sistem Informasi UMK ). Majalah IImiah Informatika, 3(1), 111-123.

Nasutio, N., \& Hasan, M. A. (2017). Aplikasi Sistem Informasi Penyewaan Fasilitas Di Universitas Lancang Kuning Berbasis Online. INOVTEK Polbeng - Seri Informatika, 2(2), 198. https://doi.org/10.35314/isi.v2i2.229 
Nasution, N., \& Hasan, M. A. (2019). I bm Pelatihan Cms Content Dan Digital J urnalistik. Dinamisia: Jurnal Pengabdian Kepada Masyarakat, 3(1), 22-30.

https://doi.org/10.31849/dinamisia.v3i1.1482

Nasution, N., Hasan, M. A., \& Setiawan, D. (2020). Sosialisasi Aplikasi Ujian Masuk bagi Calon Siswa Baru Universitas Lancang Kuning. Jurnal Laporan Abdimas Rumah IImiah, 1(1), 68-73. http://jlari.org/index.php/jlari/article/view/19

Ricky, M. Y. (2010). Analisis dan Perancangan Sistem Informasi Laboratorium Rumah Sakit Kanker Dharmais Dengan Menggunakan Total Architecture Syntesis. ComTech: Computer, Mathematics and Engineering Applications, 1(2), 561.

https://doi.org/10.21512/comtech.v1i2.2556 